\section{$\Psi$ \\ Revista \\ de Psicologia}

ISSN 2179-1740

\title{
NOTAS SOBRE O MASCULINO NO DISCURSO DA \\ MODERNIDADE A PARTIR DE DUAS OBRAS CINEMATOGRÁFICAS
}

\author{
NOTES ON THE MASCULINE IN THE DISCOURSE OF MODERNITY FROM TWO \\ CINEMATOGRAPHIC WORKS
}

\author{
Rafael Bianchi Silva ${ }^{1}$ \\ Renata Maioli Rodrigues Gastaldi ${ }^{2}$
}

\section{Resumo}

Este artigo visa discorrer sobre a masculinidade a partir de um discurso científico, tendo o ponto de vista biológico como um pano de fundo do nascimento da ciência e da moral moderna e também compreender como tais pontuações serviram de alicerce para a construção do masculino que se faz presente hoje. Utilizamos como instrumentos de análise apontamentos dos filmes Maria Antonieta e 0 Sorriso de Monalisa que demonstram valores historicamente sedimentados de uma época moderna sendo abalados. Neste sentido, tem-se o corpo como uma marca definidora de identidade. Conclui-se que repensar o masculino por essa via implica analisar a relação deste com o discurso biológico presente na construção da masculinidade e que produz efeitos ainda hoje na sociedade do século XXI. A possível quebra de paradigma aconteceu aos poucos ofertando um novo lugar para o masculino existir, possibilitando que o homem seja capaz de fazer suas próprias escolhas de identidade.

Palavras-chave: Masculinidade. Identidade. Historicidade. Papéis Sociais. Modernidade.

\section{Abstract}

This article aims to discuss masculinity from a scientific discourse, taking the biological point of view as the background of the birth of modern science and morality, and also aims to understand how such scores served as a foundation for the construction of masculine which is present today. We use as instruments of analysis the notes of the films Marie Antoinette and The Smile of Monalisa, which demonstrate the historically sedimented values mof a modern era being shaken. In this sense, this is a show the body as a defining mark of identity. It is concluded that rethinking the masculine by this way implies to analyze its relation with the biological discourse present in the construction of the masculinity and its effects still today in the society of the XXI century. The possible breakdown of the paradigm happened gradually, offering a new place for the masculine to exist, allowing man to be able to make his own choices of identity.

Keywords: Masculinity; identity; historicity; social roles; modernity

\footnotetext{
1 Professor Doutor do Departamento de Psicologia Social e Institucional e do Programa de Pós-Graduação em Psicologia na Universidade Estadual de Londrina - UEL Londrina/PR. Brasil . Rua Felício Marconi, 201 - Condominio Vale do Arvoredo Londrina/PR. Tel: (43) 999573690. Email: tibx211@yahoo.com.br. https://orcid.org/0000-0002-1170-7920

2 Professora Mestre na Faculdade Pitágoras Londrina/PR. Brasil. Email: regastaldi@gmail.com
} 


\section{INTRODUÇÃO}

O processo de construção da masculinidade na história da humanidade atravessa os tempos e perpassa por diversas influências como religiosas, culturais e sociais. Dentre os importantes atravessamentos que a constituem encontra-se também, em especial, a partir da modernidade, uma visão marcada pelo discurso científico. Tomando a anatomia sexual como base das relações sexuais e o corpo biológico como demarcador da sexualidade, a ciência delimita um modo para um ser homem e fomenta alicerces para os costumes e modos de conduta.

Assim, este artigo visa discorrer sobre a masculinidade a partir tendo como ponto de sustentação o discurso biológico, tendo como um pano de fundo do nascimento da ciência e da moral moderna e também compreender como tais pontuações serviram de alicerce para a construção do masculino que se faz presente hoje. A partir dessa proposta, acompanhamos os modos como o corpo foi constituindo-se como uma marca definidora de identidade relacionando elementos como a sexualidade envolvendo a dimensão biológica enquanto discurso que influencia diretamente o modo de vida da sociedade moderna (Laqueur, 2001 \& Bozon, 2004).

Como proposta metodológica, é realizada uma discussão a partir de artefatos culturais que, na expressão da arte, materializam e disseminam uma concepção de masculino. Compreendemos que a arte atravessa a atividade humana, configurando-se como um processo de interação entre o homem e o mundo, sendo uma forma final desta ligação, a linguagem (Argan, 1996).

Segundo Vygotsky (2001), há uma ponte entre produção e sentido sendo que ao deparar-se com uma obra, acaba-se por produzir percepções no indivíduo e assim, provocar reações. Neste viés, o artista faz experimentações com produtos de seu mundo e cria composições em torno de suas percepções das coisas e do sentido a elas conferido.

Entretanto, é importante nos ater ao fato de que a arte não revela apenas o que é belo, gerador do sentimento de conforto ou de admiração derivado da relação com tela retratada, uma escultura, poesia e outros modos. A arte comporta, também, o que nos causa admiração em seu oposto, pela via do abuso ou excesso, o bizarro, o grotesco, que como esclarece Ferreira (2010) trata-se de uma caracterização da classe estética que se faz pela via do absurdo. Logo, se por uma via nos deparamos com o belo, por outra encontramos o grotesco. 0 grotesco provoca o horror, 0 susto, o impacto e está presente em toda forma de se fazer arte, da literatura à pintura. Ao mesmo tempo em que aproxima, afasta, tendo como pontos marcantes o surpreendente e 0 fantástico, o estranho e amedrontador, construindo realidades na forma do irreal (Vazquez, 1999).

Greuel (1994) atesta que a arte empreende uma relação do belo com a percepção sensorial e, sob esta ótica, pode ser analisada a partir de três sentidos: a obra, 0 artista (que comporta o ato de produção) e o apreciador. Neste artigo, focamos na produção de objetos estéticos que funcionam como uma expressão subjetiva ao mesmo tempo em que também nos fornece um retrato de uma sociedade e de sua cultura.

Dessa forma partir dos pressupostos indicados acima, escolhemos dois filmes - "Maria Antonieta" (2006) de Sofia Coppola e "O Sorriso de Monalisa" (2002) de Mike Newell - como produção artística do tempo atual que vê, retrata e problematiza outro tempo histórico, de modo a nos mostrar os resquícios desses discursos presentificados e atualizados no momento atual. Propomos a análise das falas dos personagens que nos mostram as rupturas e continuidades em dois momentos da modernidade (século XVII e a metade inicial do século XX). Tais falas nos possibilitam apontar para os protótipos masculinos e femininos dos personagens apresentados configuram papéis 
sociais que nos permitem observar e descrever a composição de uma identidade masculina.

Em relação a identidade, Mello (1994) pontua que o conceito de identidade se sustenta por três noções importantes: a primeira traz a ideia de igualdade presente na modernidade, pautada na declaração dos direitos universais do homem; a segunda comporta uma dimensão de singularidade em que cada homem é único, ímpar e singular e; a terceira assinala a ideia de que este sujeito dito único traz em sua bagagem pessoal uma história de vida própria, a que a autora denomina biografia pessoal e que se presentifica na sua relação com os demais sujeitos nas quais se é possivel se reconhecer em sua individualidade.

Maia (2008) afirma que o indivíduo tem um sentido e que a identidade advém de uma determinada situação de existência, da ordem do ser e, portanto, diz respeito ao modo de materializar-se no mundo, em uma determinada realidade. A identidade, neste contexto, é demarcada pelas condições física e biológica, pelas marcas corporais, pelas características emocionais que definem o comportamento e o modo de agir.

Logo, vê-se que diferença e igualdade contemplam uma noção fundante de identidade, sendo, portanto, conceitos complementares. $O$ ser humano é igual aos seus semelhantes enquanto Homo sapiens e, ao mesmo tempo, se diferencia, neste sentido, dos demais animais. Como desdobramento desse processo, "[...] o conhecimento de si é dado pelo reconhecimento recíproco dos indivíduos identificados através de um determinado grupo social que existe com sua história, suas tradições, suas normas e interesses" (Ciampa, 1984, p.64).

Para além da cristalização de uma pretensa igualdade, há também na identidade a presença da ideia de metamorfose, trazendo à tona o nascimento do sujeito com a expressão do devir, vir-a-ser. Este processo de identidade como transformação do sujeito implica num novo olhar, em que o sujeito se apresenta como protagonista, como produto e produtor de si mesmo, a partir das mudanças históricas pelas quais atravessa e vivencia. Desse modo, ele não pode ser visto como algo estático, mas sim, ele é o que faz, imprimindo a marca de um processo.

O sujeito em questão é único, mas não se encontra sozinho no universo ou isolado no mundo em um processo de constituição a partir dos processos de socialização e individuação. Interage num contexto social, pertence a grupos com os quais se identifica, e possibilita a oportunidade de estabelecer trocas, estando à mercê da interferência de outros sujeitos e de outras culturas sobre sua história o que potencializa o surgimento de um novo ser. Entretanto, nas relações sociais estabelecidas, bem como os predicados configurados em papéis sociais que ela fomenta, 0 sujeito cria-se novamente, "recria-se" e se apresenta em várias identidades. Ou seja, "[...] a identidade torna-se múltipla e mutável, no entanto, una" (Ciampa, 1987, p. 61).

Tomando a identidade masculina construída nas relações sociais, Badinter (1993) afirma que os estudos de cunho científico voltados ao masculino tiveram seu apogeu em torno dos anos 1970 sendo que, até então, os homens podiam contar uma base identitária que os alicerçava com um lugar estável que veio sendo delimitado por posições e funções tradicionais impostas pela sociedade. Eram tão bem delineadas que parecia que o homem não tinha dúvidas acerca de si mesmo. A autora afirma que "[...] os homens sabiam tão bem o que eram que ninguém sequer pensava em questioná-los sobre a identidade masculina" (1993, p.6).

Somente a partir de 1990 observam-se pesquisas que "[...] inicialmente direcionaram sua atenção para a participação masculina e a responsabilidade dos homens nas questões que afetam o cuidado com os filhos e as decisões com relação à reprodução e à sexualidade" (Unbehaun, 2001, p. 632). Quando pensamos a questão da masculinidade, por exemplo, sabe-se que, durante muito tempo, houve uma expectativa em torno do filho menino, entendido como herdeiro e responsável pela perpetuação e continuidade da família a partir do sexo masculino (o que 
poderá ser observado, por exemplo, no filme Maria Antonieta que discutiremos mais adiante). Ser homem simbolizava a descendência, a manutenção do nome da prole que, por sua vez, representava a origem do núcleo familiar.

É com respaldo nessa relação do discurso científico-corpo biológico-identidade que pontuamos na análise dos filmes a presença marcante dos papeis sociais do masculino e do feminino.

\section{O DISCURSO BIOLÓGICO COMO ACENTO NA CONSTRUÇÃO DO MASCULINO NA MODERNIDADE}

Historicamente demarcada, a modernidade trazia consigo descobertas pautadas nas ciências naturais, construções de pensamentos decorrentes da Revolução Industrial do século XIX e tem seu desfecho na entrada do século XX (Giddens, 1991), sendo um berço fecundo para o nascimento da biologia. As questões sexuais gravitavam em torno do discurso científico que se firmava em novas concepções acerca da sexualidade, demarcava as diferenças sexuais e ofertava um novo modo de contextualizar o homem e a mulher.

A partir do século XVIII, com o avanço nas ciências, as questões em torno do discurso científico e do discurso médico (pautado nas considerações biológicas) ganharam espaço. Deste modo, assuntos relacionados com sexo e tabu; sexo e doenças; sexo e sensação tiveram grande demanda neste tempo e, não por acaso, o olhar ao corpo feminino também ganhou holofotes. Isso não aconteceu apenas por ser a medicina mais difundida nesta época, mas porque devido à demanda econômica e política deste século, a preocupação com as doenças e a natalidade era grande e levava a uma investigação maior da sexualidade feminina que estava ligada, a princípio, aos estudos das genitálias e ao funcionamento do corpo.

Laqueur (2001) atenta para crença que perpetuou durante anos a respeito da genitália feminina dizendo que as mulheres apresentavam a mesma genitália que os homens e que a diferença estava nos lugares opostos que se encontravam: os homens com seus órgãos sexuais voltados para fora - pênis e escroto no exterior do corpo e as mulheres com os seus - útero e ovários - para dentro, o interior do corpo. É o que se chamava de one sex model, ou modelo unissex, pensamento que se estendeu até o século XVIII.

Badintir (1993, p.8) faz uma citação de Diderot para descrever o modo como a mulher era concebida: " a mulher tem todas as partes do homem e a única diferença existente é uma bolsa pendente do lado de fora e uma bolsa voltada para dentro". A autora afirma que mesmo esse discurso trazer em certa medida a diferença sexual, a hierarquia está presente, uma vez que a mulher é comparada, mesmo sob o ponto de vista biológico, com o homem, entendido protótipo da perfeição.

Neste sentido, Birman (2001) salienta que, em torno do século XVII, surgiram os primeiros atlas de anatomia voltados aos estudos morfológicos que demarcavam a diferença entre homens e mulheres e marcavam o início de uma nova configuração anatômica, visto que, até este momento, o interesse médico permanecia focado no corpo masculino.

Enquanto, o órgão feminino estava voltado para dentro, interno, não exposto, semelhante a uma caverna, o órgão masculino era explícito, para fora, à mostra. É o homem quem adentra a caverna, é o ativo na relação sexual, um gozo visível. A passividade da mulher no ato sexual englobaria, portanto, uma característica da ordem do feminino, ao mesmo tempo em que enaltece o lugar do masculino já demarcado. Dessa forma, como bem pontua Bozon (2004), a representação do masculino e do feminino se efetiva a partir do binômio atividade/masculino e passividade/feminino, 
ultrapassando a dimensão biológica e construindo um perfil subjetivo pretensamente universal para cada um dos sexos.

Desta perspectiva, a mulher era a versão diferenciada do homem, um sexo invertido, em que confere mais uma característica que pressupõe o homem no patamar, no pódio, na ordem do superior. Silva (1999) concorda que a anatomia masculina representava um protótipo de perfeição e que o fálico, tomado como o pênis, ditava o mando de superioridade afirmando ser o homem superior à mulher e, assim, diz que as questões em torno da sexualidade têm como parâmetros e ponto inicial a anatomia masculina. Entrava em cena uma mudança de paradigma a partir da concepção two sex models: do sexo único para a visão pautada pela diferença sexual.

Guyton (1989) entende que as condições biológicas do ser humano, numa extensão da genética, fazem uso da concepção determinista e adota essa referência como um padrão universal. Por exemplo, aqueles que possuem o par de cromossomos XX são pessoas do sexo feminino e as que apresentam os cromossomos XY pertencem ao sexo masculino. Neste contexto biológico, Montgomery (2006) aponta que as diferenças sexuais são existentes e importantes, inclusive porque os hormônios - em especial, o estrogênio e a testosterona - se manifestam de formas opostas e culminam com diferenças marcantes entre os sexos.

Entretanto, a constituição cultural dessas diferenças está atravessada no desenvolvimento humano. 0 autor pontua que a forma de se relacionar afetivamente com o menino e a menina não são as mesmas. Para ele, desde a tenra infância, homens recebem toques energéticos de modo mais áspero com a presença de brincadeiras como chutes, socos, lutas que indicam a disputa e potência de forças. Já a mulher recebe informações táteis suaves em suas brincadeiras que estabelecem uma teia de sensibilidade que repercute na vida adulta e daí adjetivos como fragilidade e delicadeza configuram um perfil feminino. 0 processo pode ser observado quanto aos cuidados físicos. Enquanto a mulher volta-se para seu corpo - cabelos, pele, seios, coxas, pés e ombros, os homens "cuidam dos músculos e do pênis; genitalizam sua sensualidade, colocando sua atenção de forma fálica no pênis" (Montgomery, 2006, p.90).

O atributo que configura seu masculino está eternizado no pênis, e daí a brutalidade, agressividade e poder, conferindo ao órgão um papel simbólico-imaginário. Ser homem neste quesito não envolve ser delicado - empréstimo do feminino - e sim robusto e forte. Formula-se e dissemina-se uma ideia de homem viril que não falha, não chora e suporta os sofrimentos com braveza e coragem.

Um corte temporal nos permite observar de que modo essas concepções foram sendo modificadas. Ancorado pelas transformações sociais e políticas, a visão biológica chegou até o século XX, atravessando discussões sobre a emancipação pelos direitos das mulheres, os movimentos de luta feminina, o avanço da pílula anticoncepcional, 0 movimento hippie e a emancipação sexual colaboraram para a conquista de um lugar da mulher na sociedade não mais intrínseco ao homem.

Novas bandeiras foram levantadas e a sexualidade, antes direcionada à procriação e focada no prazer masculino, percorria agora um novo trajeto. As relações entre o homem e a mulher sofrem modificações. A mulher começa a alcançar um espaço e um lugar diferente do que ocupava. O seu ganho financeiro auxilia na economia doméstica e o casamento não é mais uma obrigação (Dias, 1997). Segundo Badinter (1985), amor e desejo ocupam o palco central dos relacionamentos e a maternidade se faz por um afeto e por uma escolha e não mais por uma imposição, nasce aí o que a autora denomina "nova mãe". Nesta via, Nolasco (1997) diz que novos papeis surgem na vida do homem também como a paternidade, uma participação maior na educação de filhos e uma presença mais 
efetiva na realização de tarefas diárias voltadas ao campo doméstico.

Entretanto, implantar esse novo modelo de vida e desconstruir posições de séculos eram tarefas complexas numa época em que se imperava um grande conservadorismo. 0 discurso biológico encontrava-se ainda muito presente e a masculinidade enraizada nas posições científicas e, em especial, no próprio tecido social.

Assim, sob o prisma das configurações de representação social e dos personagens citados, a masculinidade traz em sua dimensão um molde de representações que ganhou vida pelos discursos sociais e culturais que incrementaram a história do masculino. Ser homem, então, materializa os conceitos existentes em tempos históricos, ligados um ao outro por adjetivos e predicados que configuram o ser masculino de cada época.

\section{"MARIA ANTONIETA" E A CONSTRUÇÃO DE PAPÉIS SOCIAIS}

Consideramos que o filme Maria Antonieta (2007) de Sofia Coppola (figura 1) permite a observação de um retrato dos arranjos conjugais e o peso da sexualidade imposta por uma sociedade. $O$ drama relata a história da menina austríaca que se casou ainda muito jovem com Luís Augusto (Rei Luís XVI), herdeiro do trono francês e tornou-se uma das mais célebres soberanas da corte. Embora o foco esteja na biografia de Maria Antonieta, desenhamos um percurso em que focamos o homem pelo viés do feminino, tomando Luís XVI para observarmos 0 modelo de homem materializado e disseminado neste contexto histórico.

O que se presencia inicialmente são os casamentos arranjados, no qual, comumente, a união se dava quando o casal ainda era sem espaço algum para uma escolha para o matrimônio por outras vias que não por motivos relacionados aos interesses econômicos e políticos das monarquias.

Durante todo enredo, é possivvel observar uma identificação do sujeito a determinados papéis sociais sendo a relação homem/mulher atrelada a tais papéis e suas funções correspondentes, sendo o que é da ordem do feminino e do masculino sustentados a partir desses alicerces. Como sustenta Louro (1997, p.24):

papéis sociais são basicamente, padrões ou regras arbitrárias que uma sociedade estabelece para seus membros e que definem seus comportamentos, suas roupas, seus modos de se relacionar ou de se portar. Através do aprendizado de papéis, cada um(a) deveria conhecer o que é considerado adequado (e inadequado) para um homem ou para uma mulher numa determinada sociedade, e responder a essas expectativas.

A delimitação de papéis sociais e sua disseminação no tecido social participa do processo de cristalização e previsibilidades dos lugares que cada um precisa ocupar nas relações estabelecidas. Isso pode ser observado através das representações que circulam no campo social e que nos permitem identificar tais elementos em dado contexto histórico e cultural.

Segundo Moscovici (1981, p.181) trata-se de "um conjunto de conceitos, proposições e explicações originado na vida cotidiana no curso das comunicações interpessoais" que formam uma espécie de mitologia ou sistema de crenças que representam os objetos de modo a que seja possível (re) pensá-los e (re) experimentá-los a partir da atribuição de significados. Jodelet (2001) corrobora com tais ideias afirmando que a representação social de um objeto se faz de modo coletivo e é apreendida em um contexto social específico.

A partir disso, Oliveira (2004) pontua que características como ser valente, ser firme, ser inteligente e ser 
imponente, são adjetivos que qualificavam a masculinidade e que, ao serem associados ao masculino, assumiam um compromisso com a sociedade que se autoprojetava, então, em cima destes protótipos.

Logo, podemos perceber que a construção do papel social do homem está vinculada a um lugar de poder, o que se vê claramente na postura do Rei Luís XVI, preparado desde pequeno para o exercício do poder monárquico. Observa-se uma diferença formativa: o masculino se faz a partir dos interesses político-sociais enquanto que mulher se instaura pela via maternal. Essa concepção de tarefas e funções é mostrada numa cena em que os noivos vão literalmente para a cama para a realização das núpcias, o Rei Luís XV diz ao neto Luís XVI: "Boa sorte e bom trabalho". Neste comentário, fica clara a concepção de que ao homem (o neto) é imposta a tarefa de consumação do ato sexual fazendo jus a sua posição de macho, sendo que esta tem a finalidade de realizar o "trabalho" de engendrar um herdeiro.

Considerando a virgindade de Maria Antonieta, a efetivação do casamento pelo ato sexual poderia ser conferida diariamente de modo a retroalimentar as cobranças à jovem quanto ao papel a ser exercido naquele contexto. Uma corte toda à espera da consumação do ato sexual é demonstrada na cena da conversa de Maria Antonieta com o pajem: "Alteza, sabe quais são as consequências de um casamento real não consumado? É anulado". Em outra cena, a mãe aconselha a princesa através de uma carta: "Caríssima Antonieta: tudo depende da esposa, se ela é receptiva e carinhosa. Nunca é demais enfatizar a importância de você usar o seu charme e paciência e jamais o mau-humor para remediar essa infeliz situação. Sua posição não será sólida a menos que produza um herdeiro". A descrição das duas cenas acima nos mostra um papel ambíguo em relação a mulher: ao mesmo tempo em que, mostra-se inicialmente passiva em relação a tarefa colocada ao homem, ela é responsabilizada pelo seu possível fracasso. Nessas falas observa-se a hierarquia masculina, não há endereçamento algum ao homem por não ter filhos.

Assim, a possibilidade de falibilidade não é do homem, mas sim da mulher, seja na incapacidade de ser receptora da potência sexual masculina ou ainda na dificuldade ou impossibilidade de gerar filhos. Observa-se aqui que a imagem passada pela obra é que Maria Antonieta retrata a mulher de um tempo cujo interesse maior era gerar filhos - ou herdeiros - para o trono da coroa da França.

Nesta sociedade, o filho homem era esperado e extremamente desejado para assumir um lugar que já estava determinado e sublinhado pelo exercício do poder. Quanto a Luís XVI, por sua vez, encarna o protótipo do homem poderoso onde exercer sua masculinidade estava vinculado ao governo, tomar as rédeas da administração do reino da França, ou seja, o empoderamento dava-se pelo trabalho de governar e não na incapacidade de ter filhos. Gerar herdeiros não dizia de si, mas de sua esposa. Se ele não era falho, então, a não geração de filhos, mostrava a possibilidade de ela ser frígida. Entre os corredores de Versailles o que se escutava, como retratado em uma outra cena do filme, era: "Dizem que ela é seca". Mas nada é falado a respeito de Luís XVl: sua posição como macho não era motivo de dúvida. Se havia algum problema da ordem sexual, com certeza não estava voltado a ele enquanto homem e sim a Maria Antonieta, vista como frígida, seca, infértil.

Observa-se que os problemas em torno da incapacidade inicial de gerar filhos são direcionados sempre à mulher e não ao homem. A questão em torno do sexual era da ordem da maternidade, não do masculino. A construção acerca do biológico e do social se faziam presentes e atuantes neste contexto.

Quanto a presentificação do papel masculino, o rei Luís XVI teria, segundo Zweig (2013, p.20): "uma inteligência limitada, era tido como grosseiro e totalmente insensível". No filme, a grosseria é velada e aparece em seu 
comportamento indiferente em relação à esposa. 0 rei realiza os desejos supérfluos de Maria Antonieta mas o que parece é que não se trata de amor e sim de uma fórmula pela qual impõe uma estratégia de afastar a esposa de si e de deixá-lo em paz, livre para atirar-se às suas caças colocando a rainha num lugar de mulher fútil que se contenta com presentes em troca do calar-se e não criar perturbações.

Privado e público eram espaços prontamente determinados para acesso e circulação de atores específicos. Nesse contexto, as mulheres não ocupavam os mesmos espaços que os homens. Não foi por acaso que o rei presenteou a rainha com o Petit Trianon, localizado em Versailles, para que ela pudesse desfrutar de prazeres sociais - apresentações de teatro, música e celebrações religiosas na capela particular - e mantê-la afastada das organizações e reuniões políticas. Tem-se, então, o masculino e o feminino bem representados em seus personagens endossando características peculiares que repercutem em comportamentos distintos do que é ser homem e ser mulher.

\section{O SORRISO DE MONALISA E A POSSIBILIDADE DE QUEBRA DE PARADIGMAS}

Neste mesmo viés em torno da representação social e para tornar mais claro os aspectos da modernidade em meados de 1950, podemos citar o filme 0 Sorriso de Monalisa, de Mike Newell, tomado como o reflexo de uma época, que interroga os papéis possíveis de homens e mulheres.

A personagem central do drama é a professora de arte Katherine (também referenciada em alguns momentos como Kathe) que leciona numa escola tradicional americana voltada exclusivamente para moças. Na época em que se passa a história do filme, tanto no Brasil quanto em alguns países da Europa, era comum encontrar escolas que atendiam o público feminino separado do público masculino. Ainda hoje em nosso país encontramos essa formação dicotomizada inclusive nas atividades ensinadas como disciplinas.

O filme mostra que a professora tem suas raízes numa escola liberal da Califórnia e conserva em si ideias para um tempo além do seu. $O$ conflito se torna real a partir do momento que percebe em suas alunas um potencial além do casamento e da maternidade. 0 que é intrigante é que não há, por parte da professora, uma decisão entre se casar e ter filhos ou ser uma profissional. Pelo contrário, a professora vê a possibilidade de suas alunas exercerem as duas funções, o que soa como uma aberração para todo campus escolar e a sociedade em geral sendo constantemente hostilizada pelos colegas, professores e suas próprias alunas. O lugar indicado pela sociedade da época para a mulher seria o de doméstica prendada e o título como num concurso de misses seria de "A Rainha do Lar".

Em uma cena do filme, uma de suas alunas ao visitar a casa da amiga recém-casada sente-se encantada pela cozinha e lavanderia toda equipada e comenta: "Nossa! Isso é tudo com o que sempre sonhamos". Já para Kathe a atmosfera em torno do campus lhe causa incomodo diante de tantas demarcações, protótipos da modernidade, e em outra cena ela afirma: "Existem muitos rótulos aqui: família certa, escola certa, arte certa, forma certa de pensar".

Embora a professora seja a protagonista da trama, utilizo-me desta obra com a finalidade de apontar 0 masculino em diversas cenas do filme. Quatro personagens masculinos com características que acentuam o que é ser homem nos anos 50 e como a masculinidade estava inserida. A fala de Tommy, o noivo de Joan (uma aluna que demonstra o desejo de fazer o curso de Direito na Universidade de Yale) contempla todo pensamento dogmático e tradicionalista da época, quando ele afirma: "Agradeço a professora pelo incentivo, mas minha namorada não poderá cursar Yale. A distância é longa e não dará tempo para ela servir o jantar antes das cinco". 
Dentro deste contexto, o homem é aquele que ainda governa e autoriza comportamentos em casa, tanto que, em uma cena, em uma das lições de um curso de etiquetas na escola a professora diz às alunas: "A nota mais importante da vida de vocês será a nota que ele (o marido) vai lhe dar" (Fig.2).

Outra cena envolve o professor Bill que tem casos amorosos com suas alunas e com a própria professora de arte ao mesmo tempo. Observa-se que no envolvimento com a aluna, o professor apresenta-se como um homem adulto, dono de si, que compõe o perfil de um homem galanteador, dotado de um saber supremo e que encanta os corações das donzelas por apresentar-se como um bom partido e um homem maduro. Em relação ao romance com a professora, aparece uma necessidade de enveredar-se numa mentira em relação aos feitos em sua trajetória de vida. Ele mente sobre ter vivido na Europa e ter conhecido novas culturas, uma vez que nunca havia saído de seu próprio país onde lecionava, o que demonstra suas inseguranças e fragilidades em não estar à altura ou no mesmo patamar do que a professora Kathe, colocando-se em um lugar menor e num suposto grau de inferioridade. Como diz Bill em uma das cenas: "As mulheres precisam de heróis, Kathe. Não é fácil com você". Ou seja, o saber pertencia ao homem enquanto à mulher, fogões e utensílios domésticos, jantares, fraldas e mamadeiras, seriam o mais próximo que ela poderia almejar. Tanto que havia por parte do colégio Wellesley uma permissão para que as alunas faltassem às aulas quando se casavam.

Ainda há dois homens que traem suas esposas representando a moralidade hegemônica na época acerca do casamento e da sexualidade. Ao olhar desses homens, dividem-se aí dois tipos de mulheres: aquela formada para casar e outra com quem se tem um bom sexo, retomando o preceito de diferenciação feminina entre mulheres santas e ímpias que pode ser observado no discurso bíblico do Antigo Testamento.

Assim, o comentário de Betty, presente em uma das cenas, em relação ao comportamento da colega de quarto que sai com um homem casado reflete o pensamento moral acerca da moça ideal para casar e daquela que não mais virgem, só serve para deleite dos homens: "Dizem que você é uma prostituta, que depois que todos te usarem você ficará como um trapo velho. Os homens não vão querer você".

Figuram neste desfile a bendita ou a maldita, a santa ou a profana, a prostituta ou a dona de casa. Já o papel social atribuído ao homem não acolhe essa dupla versão: ele não comporta ou isto ouaquilo. Sustenta os dois padrões dentro de si mesmo abarcando os dois lados de uma mesma moeda. Nesta sociedade ele não precisa optar em ser um ou outro: ele é. É o bom moço e também o mau sendo que os casos extraconjugais - considerados socialmente como traições -, de sua parte, são permitidas.

Neste quesito, ainda no filme, encontramos um homem atípico para os padrões da época, Charlie o aluno nerd, romântico e protótipo do homem sincero e respeitador com os desejos da mulher. Podemos observá-lo como um homem fora de seu tempo onde tais características causam discreto desconforto em outros homens e até mesmo um possivel estranhamento para algumas mulheres diante de atitudes circunscritas socialmente como mais femininas para a ordem do masculino. Considerando a ausência de um lugar de destaque no filme para tal personagem, observamos a partir disso que tal modo de conduta não se configurava como protótipo de masculinidade, não merecendo destaque no discurso hegemônico da época.

Desse modo, ainda que sob a possibilidade de encontrarmos diferentes elementos que escapam à concepção hegemônica, a representação social da masculinidade atravessa os tempos e elege uma configuração para se expressar. Vindo de uma sociedade cujo modelo verte pelo patriarcado, Nolasco (1997) afirma que a masculinidade converge para a representação do "homem de verdade", em que meninos e meninas se baseiam em uma crença de 
que são o que são por um destino da natureza. A representação social de masculinidade advém desta configuração de influências e vivências sendo atualizadas e reproduzidas no dia-a-dia pelas relações cotidianas.

\section{CONSIDERAÇÕES FINAIS}

Podemos concluir que a identidade masculina construída na modernidade foi pautada nas relações sexuais respectivamente simbolizados no pênis e na vagina como referenciais. Isso acarretou uma marca identitária que fomentou uma imagem estereotipada de peso e que se fez atuante no modo de agir e de ser masculino, de alguma maneira, presente ainda hoje. As mudanças ocorridas a partir da modernidade foram significativas e trouxeram uma implicação direta no comportamento masculino o que se traduz num novo modo de ser na contemporaneidade.

Observa-se que há uma dificuldade na definição de uma identidade masculina contemporânea que se funde em diversificados papéis acerca do que é ser homem. O homem trouxe em sua composição uma história inscrita por expectativas, tradição ou desígnios de um masculino em ação para perpetuar a espécie. Deste modo, foi disseminado, sob a justificativa científica, um homem alicerçado por dogmas morais em suas atitudes e de comportamentos rígido e conservador. Encontramos na contemporaneidade um paradoxo: uma crise da masculinidade que pré-anuncia um novo homem que não precisa ser "ou isto, ou aquilo", mas "isso, aquilo e o que mais quiser", o que coloca enquanto possibilidade, inclusive, abrir mão do sexo masculino.

Até aqui, pudemos compreender que duas visões de pensamento se instalaram: a visão biológica e a visão social de ser homem, da ordem do masculino e que culminaram com estudos de gênero a partir da metade do século $X X$ que se estendeu com força no século XXI. Embora se concretizem as conquistas e apareça um novo olhar sobre 0 modo de vivenciar a sexualidade, a paternidade e os laços matrimoniais, nos deparamos ainda com um homem dogmático e aparentemente inflexível que faz rumores no tempo atual, um homem ainda apegado ao caminho cultural e aos reforços contraditórios que foram sendo traçados em torno da masculinidade em todos esses séculos (Nolasco, 1997). Em pleno século XXI, a honra para alguns homens que atestam sua masculinidade ainda se apresenta na conjugação dos verbos "possuir" e "ter" o que faz com que os vestígios de uma masculinidade endurecida se sobressaiam.

Por outro lado, no palco da chamada pós-modernidade a configuração de uma identidade flexível fragmenta geram outras possibilidades de ser. Entretanto, tais fragmentos não precisam ser tomados pela negatividade. A questão da crise da masculinidade se dá muito mais pelas múltiplas escolhas do que pela insegurança de não se ter um modelo a que escolher. Não é a falta de um modelo, mas a possibilidade de muitos. Talvez o desconforto se pontue exatamente aí. De uma situação fragmentada, possibilidades positivas podem surgir: de um masculino uno para um múltiplo, novas masculinidades então prestes a nascer. Assim, as contradições que culminaram com a crise demarcada não são de todo algo tão ruim, uma vez que favoreceram novas composições acerca da masculinidade, formularam novas maneiras de se viver.

Não há um ponto de quebra de uma passagem à outra (da modernidade para a pós-modernidade; ou de um século a outro), mas há alterações nas visões de mundo que vão se infiltrando, capilarizando, de forma a promover uma nova maneira de se vivenciar a masculinidade. Os movimentos não são totalitários, não são únicos. São múltiplos e dinâmicos. 
As fronteiras de uma masculinidade já estruturada se apresentaram por muito tempo como barreiras ao novo. O positivo de toda essa construção é averiguar que o masculino na contemporaneidade tem outros enveredamentos. De um homem provedor financeiro para um homem gerenciador de seus próprios afetos capaz de se desdobrar em várias facetas e abarcar outras funções além das já existentes e declaradas masculinas. Um homem que tem nas mãos a possibilidade de sua própria escolha de identidade, uma identidade plural.

\section{REFERÊNCIAS:}

Badinter, E. (1985). Um amor conquistado: o mito do amor materno. Rio de Janeiro: Nova Fronteira.

Badinter, E. (1993). XY: sobre a identidade masculina. Rio de Janeiro: Nova Fronteira.

Birman, J. (2001). Gramáticas do erotismo: a feminilidade e as suas formas de subjetivação em psicanálise. Rio de Janeiro: Civilização Brasileira.

Bozon, M. (2004). Sociologia da sexualidade. Rio de Janeiro: FGV

Ciampa, A. C. (1984). Identidade. In: Lane, S. T. M., \& Codo, W. (Orgs.). Psicologia Social: o homem em movimento. São Paulo: Brasiliense.

Ciampa, A. C. (1987). A estória do Severino e a história da Severina. São Paulo: Brasiliense.

Dias, M.L. (1997). Vivendo em família: relações de afeto e conflito. São Paulo: Moderna.

Giddens, A. (1991). Modernidade e identidade. Rio de Janeiro: Zahar.

Guyton, A. (1989). Tratado de Fisiologia Médica. Rio de Janeiro: Guanabara.

Jodelet, D. (2001). Representações sociais: um domínio em expansão. In. Jodelet, D. (Org.). As representações sociais. Rio de Janeiro: EdUERJ.

Laqueur, T. (2001). Inventando o sexo: corpo e gênero dos gregos a Freud. Rio de Janeiro: Relume-Dumará.

Lemos, F. (1997) A representação social da masculinidade na religiosidade contemporânea. Revista Netmal, 1,7-17.

Louro, G. L. (1997). Gênero, sexualidade e educação: Uma perspectiva pós-estruturalista. Petrópolis: Vozes.

Maia, R. D. (2008). O conceito de identidade na filosofia e nos atos de linguagem. Mestrado em linguística, UFSCar, São Carlos, SP. Disponível em: https://repositorio.ufscar.br/handle/ufscar/5661. Acesso em: 10 fevereiro 2017. 
Mello, S. L. (1994). Pensando o cotidiano em ciências sociais: identidade e trabalho. Cadernos CERU, série 2, n.5, p.23-31.

Montgomery, M. (2006). A mulher e seus hormônios... Enfim em paz. São Paulo: Integrare.

Moscovici, S. (1981). Representación Social. In J. P. Forgas (Ed.), Social Cognition perspectives on everyday knowledge (pp.181-209). London: Academic Press.

Nolasco, S. (1997). Um homem de verdade. In: D. Caldas (org.). Homens. São Paulo: Editora Senac.

Oliveira, P.P. (2004). A construção social da masculinidade. Belo Horizonte: UFMG.

Silva, S. G. (1999). Masculinidade na história: a construção cultural da diferença entre os sexos. Psicologia: Ciência e Profissão,20(3).

Unbehaun, S. (2001). Paternidades e masculinidades em contextos diversos. Revista Estudos Feministas, $9(2)$. Disponível em https://dx.doi.org/10.1590/S0104-026X2001000200023

Zweig, S. (2013). Maria Antonieta, retrato de uma mulher comum. Rio de Janeiro: Zahar 


\section{Lista de Figuras}

Figura 1 - Luís XVI e Maria Antonieta em cena do filme Maria Antonieta de Sofia Coppola.

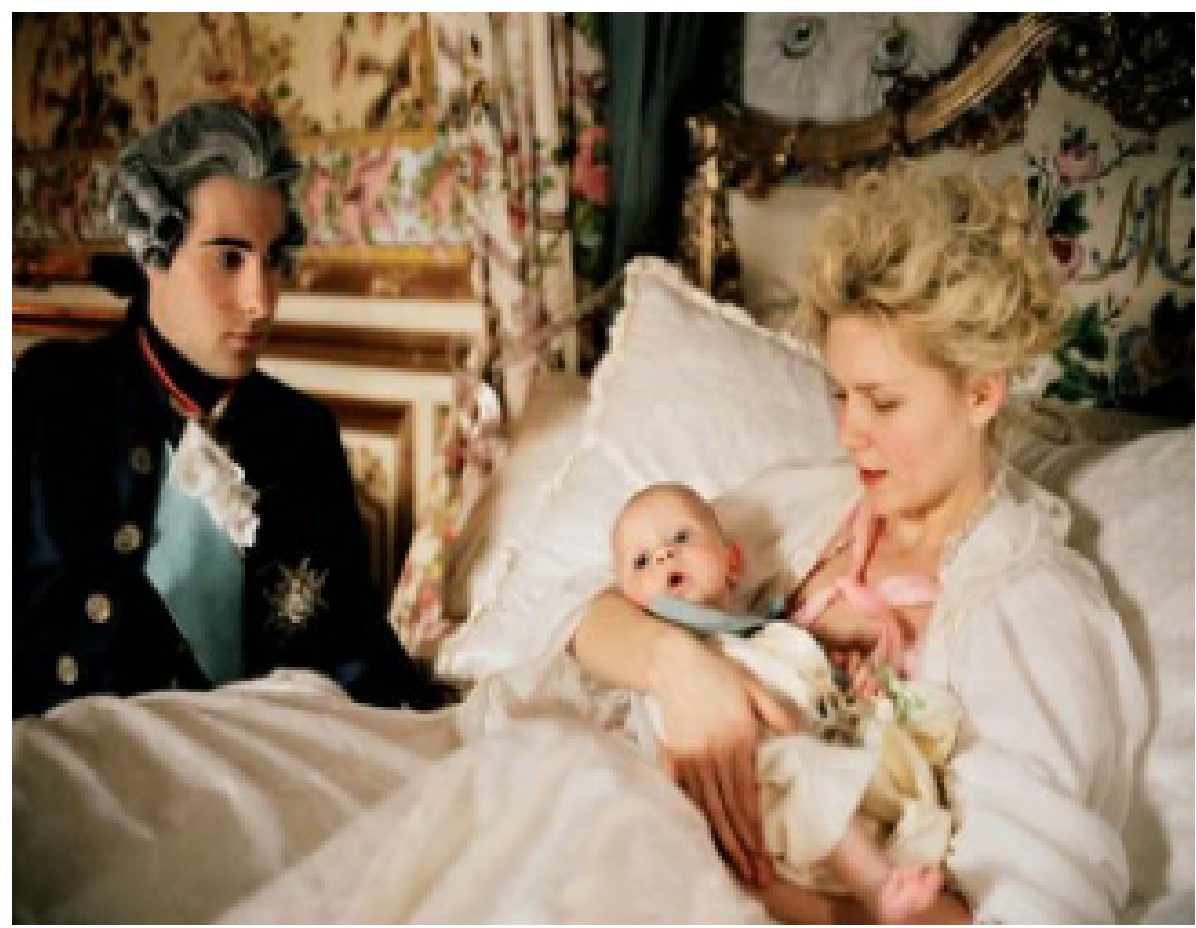

Figura 2 - Cena do filme O Sorriso de Monalisa (2003), de Mike Newell

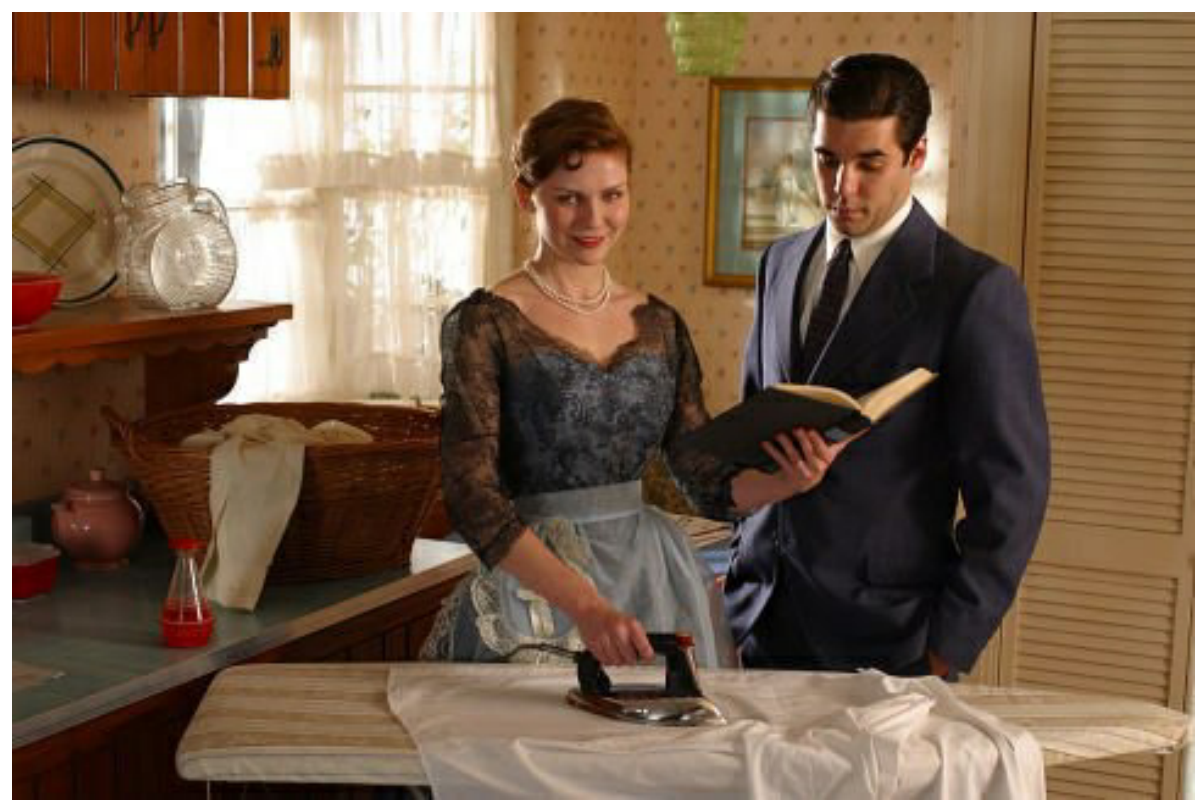

